\title{
Biodiesel Production in Batch Tank Reactor Equipped to Helical Ribbon-like Agitator
}

\author{
Mehdi Hosseini \\ Dept. of Mechanical Engineering in Agriculture Machinery, Faculty of Agriculture \\ Urmia University, Urmia, Iran
}

Tel: 98-91-4164-8733_E-mail: mehdihosseiny84@yahoo.com

Ali Mohammad Nikbakht (Corresponding author)

Assistant professor, Dept. of Mechanical Engineering in Agriculture Machinery, Faculty of Agriculture

Urmia University, Urmia, Iran

Tel: 98-91-2638-9682Ｅ-mail: a.nikbakht@urmia.ac.ir

Meisam Tabatabaei

Assistant professor, Dept. of Microbial Biotechnology and Biosafety, Agricultural Biotechnology Research Institute of Iran (ABRII)

Tel: 98-91-3286-5342_E-mail: meisam_tab@yahoo.com

Received: December 12, 2011

doi:10.5539/mas.v6n3p40
Accepted: January 20, 2012 Published: March 1, 2012

URL: http://dx.doi.org/10.5539/mas.v6n3p40

\begin{abstract}
Biodiesel as an alternative and renewable fuel could be applied in diesel engines in order to reduce air contamination and dependence to fossil fuels. So far, various processes were prepared for biodiesel production, but using transesterification method via base catalyst in batch reactors could result in a reasonable yield of biodiesel. At the present study, a batch tank reactor equipped to a helical ribbon-like agitator was designed and manufactured. Using this reactor, the production efficiency was considerably promoted and the required residence time was reduced. Experiments were conducted at 6:1 molar ratio of alcohol to refined soybean oil, operational temperature of $64{ }^{\circ} \mathrm{C}, \mathrm{KOH}$ concentration of $1 \% \mathrm{wt}$ oil, and three levels of agitation speed; 600,750 , and $900 \mathrm{rpm}$. The agitator design and its helicon movement led to a uniform phase formation of insoluble alcohol and oil. Therefore, at $900 \mathrm{rpm}$ stirring speed and after $20 \mathrm{~min}$ residence time, $97.3 \%$ conversion of triglycerides to methyl esters (biodiesel) could be achieved.
\end{abstract}

Keywords: Biodiesel, Transesterification, Reactor, Agitator, Ribbon-like

\section{Introduction}

Increasing the price of petroleum, environmental concerns about vehicle exhausts, local changes in atmosphere and upward trend to use diesel engines, due to their better performance compared to gasoline engines, have been major reasons for the extension of biodiesel as an alternative fuel (Marchetti, et al., 2005). Additionally, depletion of oil reservoirs and strict regulations on exhaust emissions have necessitated the substitution of fossil fuels with less polluting and easily available renewable fuels for use in internal combustion engines (Sahoo \& Das, 2009).

The most common method in biodiesel production is transesterification of plant oils in batch mode at operational temperature of near to alcohol boiling point. In a stoichiometric process of transestrification, three moles of methanol react with one mole of triglyceride (TG) usually in the presence of a base catalyst (usually $\mathrm{NaOH}$ or $\mathrm{KOH}$ at the concentration of $0.1-1 \% \mathrm{wt}$ oil), resulting in the production of a mono- methyl ester and co-production of glycerol. In order to well proceeding the reaction, extra alcohol is used commonly at 6:1 molar ratio of alcohol to oil (Van Gerpen, et al., 2002-2004, Noureddini, et al., 1998). Yet, there are some technical challenges facing biodiesel production via transesterification, which include long residence times, high operating 
cost and energy consumption, and low production efficiency. In recent years, studies on biodiesel synthesis have focused on development of process intensification technologies to resolve some of these issues (Zheyan Qiu, et al., 2010).

As a result, numerous studies have been conducted focusing on the kinetics of the methanolysis in order to achieve the best reactor designs to overcome the above-mentioned shortcomings as well as economizing the whole process (Reyes, et al., 2010). In order to achieve that, when designing a reactor, important elements including the size of the reactor (reactor dimensions), construction material, the agitation system, hydrodynamic studies, physical properties of reactants, and the method of supplying or removing heat should be taken into consideration (Harriott, 2003; Azhari, et al., 2008). Some various agitators which have been commercially used so far for improving the biodiesel production process in batch mode and reducing the reaction time include: mechanical stirrers (Freedman, et al., 1984; Noureddini \& Zhu, 1997), magnetic stirrers (Darnoco \& cheryan, 2000; Mittelbach \& Trathnigg, 1990; Komers, et al., 2002), turbines (Ma, et al., 1999), two motionless mixers combined with a high shear mixer (Noureddini, et al., 1998), anchor (Alcantara, et al., 2000), Rushton turbine (Blottnitz, et al., 2004), helix (Vicente, et al., 2005), and two flat-blade paddles (Olivera, et al., 2007).

In this study, a type of batch stirred tank reactor (BSTR) was designed and manufactured. To solve mass transfer limitations between alcohol and oil, an especial kind of mechanical agitator was designed and manufactured. Having an optimized process of transesterification reaction, production efficiency was meaningfully improved compared to similar reactors.

\section{Material and Methods}

\subsection{Design and Manufacturing}

A special type of BSTR was designed and fabricated at Urmia University (Figure 1). For conducting transesterification reaction, one cylindrical stainless steel reactor with $3 \mathrm{~mm}$ thickness, $220 \mathrm{~mm}$ internal diameter, $450 \mathrm{~mm}$ height, and 20 liter volume was used. A conical part with $150 \mathrm{~mm}$ height, in order to homogenizing reactants mixing and phase separation in separating glycerol and biodiesel as well as separating biodiesel and soap was attached to the ending point of cylindrical tank. A frontal transparent section (from methyl methylacrylat with $6 \mathrm{~mm}$ thickness) was designed to observe and monitor the reaction. Flexibility and residence to corrosion against corrosive materials which will present into the reactor were two main reasons for the selection of this polymer.

Actually, agitation is substantial in the sense of phase formation and separation processes. A type of stirrer called helical ribbon-like stirrer from stainless steel material was designed and manufactured (Figure 2). Its internal and external diameters were $140 \mathrm{~mm}$ and $200 \mathrm{~mm}$, respectively. The width of the belt was $30 \mathrm{~mm}$ and its thickness was $2 \mathrm{~mm}$. A heating system was prepared to heat the liquid and maintain temperature at a desired value. The heating system was equipped to two 1000 watt steel heaters, a PT100 temperature sensor, and control panel. A 1 $\mathrm{kW}$ electric motor integrated with an inventor was applied driving the stirrer via a belt-pulley transmission path. Maximum speed of $900 \mathrm{rpm}$ could be achieved for the agitator.

\subsection{Experimental Procedure}

Experiments for finding optimal production conditions were planned. All experiments were conducted at 6:1 molar ratio of alcohol to oil and $1 \% \mathrm{wt} \mathrm{KOH}$. According to previous researches, optimal temperature for production in batch mode was selected at temperature near to alcohol boiling point, $64{ }^{\circ} \mathrm{C}$. The purpose was specification of optimal stirring speed for production and also consideration of produced fuel quality at optimal condition. Refined soybean oil with $0.92 \mathrm{~g} / \mathrm{cm}^{3}$ density at volume of 6.5 liter for each test was fed to the reactor in the presence of methanol as an alcohol. We assumed that refined soybean oil is pure triolein. Thus, its molecular weight was assumed $889.46 \mathrm{~g} / \mathrm{cm}^{3}$. KOH catalyst and methanol were primarily mixed and the obtained methanol $/ \mathrm{KOH}$ solution was added to oil into the reactor. This adding would effective due to hot exothermic reaction. Moreover, achieved mixture was heated up to $64{ }^{\circ} \mathrm{C}$ and agitated with pre-specified rotation speed. Experiments according to changing stirrer speed in three levels; 600, 750, and $900 \mathrm{rpm}$ were planned. With starting the agitation, transesterification between methanol and soybean oil in the presence of $\mathrm{KOH}$ began. After starting the agitation, one sample with $50 \mathrm{~mL}$ volume was extracted in the intervals of $10 \mathrm{~min}$. Agitation was performed until $60 \mathrm{~min}$. the mixture color was milky at the first phases of the reaction tending to yellow like brown as the process went on. This state maintained robust until the end of the reaction. After passing 1 hour of the reaction, agitation was stopped and phase separation between the biodiesel and glycerol started. For separation of more than $90 \%$ glycerol, 3-4 hours is required. After that, glycerol was sediment due to higher density. After phase separation, water washing and refining the biodiesel was performed. Warm water at the temperature of $50-60{ }^{\circ} \mathrm{C}$ was used as it prevents settling the saturated fatty acid esters (saturated biodiesel), 
delays formation of emulsion and accelerates and completes the phase separation (Van Gerpen, et al., 2002-2004). Amount of water that is required for each water washing is about 2 times of produced biodiesel. Number of water washing is related to oil quality and accuracy in performing the reaction. For fresh oils, 2-3 times and for waste oils 5-7 times water washing is required. Transparency of waste water is a good criterion to finish the water washing process. For naturalization of biodiesel yield and removing its $\mathrm{KOH}$ content, initially $\mathrm{H}_{2} \mathrm{SO}_{4}$ acid was added to water. Amount of required $\mathrm{H}_{2} \mathrm{SO}_{4}$ was specified by adding acid at small amounts and subsequently measuring biodiesel $\mathrm{pH}$ until reaching its $\mathrm{pH}$ to about 7. Measuring $\mathrm{pH}$ was done using a set of $\mathrm{pH}$ meter, AZ86502. Reaction of triglycerides with water produces fatty acids and subsequently, reaction of fatty acids with $\mathrm{KOH}$ produces soap which forms a white phase that could be separated easily. For mixing the water with unrefined biodiesel and solute impurities into water, agitating is required. In the case of reactor, after twice water washing during $10 \mathrm{~min}$ agitation for each washing process, transparence waste water was achieved whereas using vacuum pump for samples, number of washing process boosted up to 5 times. Refined biodiesel has small amounts of water that causes to its color became opaque. With placing the samples on a constant place, after 48 hours, water content settled and transparence biodiesel was achieved.

In order to find produced biodiesel yield content and achieve the value of conversion percentage of triglycerides to methyl esters, gas chromatography (GC) analysis was conducted so that optimal agitation speed with consideration of biodiesel synthesis and reaction time were obtained. GC analysis was performed in chemistry analysis laboratory of Urmia University. Percentage of conversion was calculated using Eq.2.

$$
\% \text { produced biodiesel }=\frac{\% \text { FAMEyield } \times \text { weight of product }(\text { gram })}{\% \text { FAMEyield } \times \text { weight of crude material }(\text { gram })}
$$

Various fuel tests were done on the optimal sample in biodiesel research laboratory of Tarbiat Modares University. Results were compared with ASTM D6751 and EN14214 standards.

\section{Results and Discussion}

Mass transfer which related to agitation quality is a very important factor in the reaction and generally in reactor performance. Figure 3 shows the effect of agitation speed in three speed levels; 600, 750, and $900 \mathrm{rpm}$ at the operational temperature of $64{ }^{\circ} \mathrm{C}$ (temperature near to methanol boiling point) on biodiesel yield. Many researchers have indicated that this temperature is optimal in BSTRs (Leevijit, et al., 2006).

According to Figure 3, more than $85 \%$ conversion could be achieved after passing 10 min of the reaction. Also, there is a significant difference between produced biodiesel at 10 and 20 minutes. After 20 min of reaction, progress of conversion decreased and reached to equilibrium gradually. With starting the agitation, transesterification between the oil and methanol in the presence of $\mathrm{KOH}$ began. First, reaction rate due to low solubility of alcohol and oil is slow. At the second step following by dissolution of them, reaction rate increases and finally with consuming the reactants decreases and got to equilibrium state.

The progress of producing the yields in each of above graphs with increasing agitation speed up to $900 \mathrm{rpm}$ was meaningful while at higher speeds, significant increase in production of methyl esters was not likely to occur. Increasing the agitation speed is highly associated with increasing the contacts of oil and alcohol molecules leading to vigorous mass transfer. Mass transfer is a critical step in limitation of transesterification. Higher agitation speeds leads to higher conversion and lower required reaction time. However, at higher agitation speeds, the reaction rate is prone to decrease (Noureddini, et al., 1998).

At the $900 \mathrm{rpm}$ agitation speed, after passing $20 \mathrm{~min}$ of reaction time, $97.3 \%$ conversion of triglycerides to biodiesel was achieved that matched with biodiesel standards. According to EN14214 standard, 96.5\% conversion is necessary at least. By increasing the reaction time, value of conversion increased. After 60 min of agitation with $900 \mathrm{rpm}$ speed, concentration of methyl esters got to $99.8 \% \mathrm{wt}$ of oil. Therefore, for biodiesel production with standard conversion, 20 min was adequate.

Required reaction time for obtaining required conversion in batch reactors was reported $20 \mathrm{~min}$ to 2 hours by many researchers (Van Gerpen, et al., 2002-2004; Noureddini, et al., 1998; Refaat, et al., 2008). Therefore, the present reactor was able to produce favorite conversion under minimum reaction time thus pending low capital cost. The reason lies in the good performance of stirrer in mixing of two initial insoluble reactants. Special design of this stirrer and its helicon movement incorporated alcohol and oil phases together and removed phase boundary between them. With removing this boundary each alcohol and oil particles permeated to another and transesterification began. As a consequence, the necessity to circulation pump which is common in these types of reactors was removed i.e. less energy would be required to yield a pure biodiesel. Continuous upward flow of the material in helical ribbon-like stirrer enhanced the agitation significantly as the turbulence and disturbance 
phenomena are intensified leading to better contacts between phases. Moreover, a thin layer of the material between the stirrer and inner surface of the reactor incorporated with a shearing effect caused a micro mixing. This phenomenon has a positive effect in agitation. The sample which was achieved after 20 min of reaction time under operational temperature of $64{ }^{\circ} \mathrm{C}$ and $900 \mathrm{rpm}$ stirrer speed was selected as an optimal sample. Various fuel tests were done on that sample. Results and comparison of them with ASTM D6751 and EN14214 are detailed in table1. As presented, the produced fuel has compatibility with Europe and USA standards. Therefore, the present technology due to low production costs, easily scaled up and also production of high quality fuel, is highly proposed in industrial applications.

\section{Conclusion}

A type of BSTR equipped to unique helical ribbon-like stirrer was with designed and manufactured. A desirable ability of stirrer in mixing two insoluble alcohol and oil phases led resulted in a considerable reduction of required time. Performance temperature of $64{ }^{\circ} \mathrm{C}$, agitation speed of $900 \mathrm{rpm}, 6: 1$ molar ratio of alcohol to oil, and in presence of $\mathrm{KOH}$ with concentration of $1 \% \mathrm{wt}$ of oil, were ideal parameters which differentiates it with other similar reactors. As the lower energy consumption of the system, it can be an optimized option for being employed in industrial sections.

\section{References}

Alcantara, R., Amores, J., Canoira, L., Fidalgo, E., Franco, M. J., \& Navarro, A. (2000). Catalytic production of biodiesel from soybean oil, used frying oil and tallow. Biomass Bioenergy, 18, 515-527. http://dx.doi.org/10.1016/S0961-9534(00)00014-3

Azhari, T. I., Mohd Ghazi Gunam Resul, M. F. M., Yunus, R., \& Shean Yaw, T. C. (2008). Preliminary design of oscillatory flow biodiesel reactor for continuous biodiesel production from jatropha triglycerides. Journal of Engineering Science and Technology, 3(2), 138-145.

Darnoko, D., \& Cheryan, M. (2000). Kinetics of Palm Oil Transesterification in a Batch Reactor. Paper no. J9574 in JAOCS, 77, 1263-1267.

Freedman, B., Pryde, E. H., \& Mounts, T. L. (1984). Variables affecting the yields of fatty esters from transesterified vegetable oils. J Am Oil Chem Soc, 61, 1638-43. http://dx.doi.org/10.1007/BF02541649

Harriott, P. (2003). Chemical reactor design. Cornell University Ithaca. New York, U.S.A.

Komers, K., Skopal, F., Stloukal, R., \& Machek, J. (2002). Kinetics and mechanism of the KOH-catalyzed methanolysis of rapeseed oil for biodiesel production. Eur. J. Lipid Sci. Technol, 104, 728-737. $\mathrm{http}: / / \mathrm{dx}$. doi.org/10.1002/1438-9312(200211)104:11<728::AID-EJLT728>3.0.CO;2-J

Leevijit, T., Wisutmethangoon, W., Prateepchaikul, G., Tongurai, C., \& Allen, M. (2006). Design and test of a continuous reactor for palm oil transesterification. Songklanakarin J. Sci. Technol, 28(4), 791-802.

Ma, F., Clements, L. D., \& Hanna, M. A. (1999). The effect of mixing on transesterfication of beef tallow. Biores. Technol, 69, 289-293. http://dx.doi.org/10.1016/S0960-8524(98)00184-9

Marchetti, J. M., Miguel, V. U., \& Errazu, A. F. (2005). Possible methods for biodiesel production. Renewable and Sustainable Energy Reviews, 11, 1300-1311. http://dx.doi.org/10.1016/j.rser.2005.08.006

Mittelbach, M., \& Trathnigg, B. (1990). Kinetics of alkaline catalyzed methanolysis of sunflower oil. Fat. Sci. Technol, 92, 145-148.

Noureddini, H., \& Zhu, D. (1997). Kinetics of transesterification of soybean oil. JAOCS, 74, 1457-1463. http://dx.doi.org/10.1007/s11746-997-0254-2

Noureddini, H., Harkey, D., \& Medikonduru, V. (1998). A Continuous Process for the Conversion of Vegetable Oils into Methyl Esters of Fatty Acids. JAOCS, 75(12). http://dx.doi.org/10.1007/s11746-998-0331-1

Olivera, S., Stamenkovic, M. L., Lazic, Z. B., Todorovic, V. B., Veljkovic, D. U., \& Skala. (2007). The effect of agitation intensity on alkali-catalyzed methanolysis of sunflower oil. Bioresource Technology, 98, 2688-2699. http://dx.doi.org/10.1016/j.biortech.2006.09.024

Qiu, Z. Y., Zhao, L. N., \& Weatherley, L. (2010). Review: Process intensification technologies in continuous biodiesel production. Chemical Engineering and Processing, 49, 323-330. http://dx.doi.org/10.1016/j.cep.2010.03.005

Refaat, A. A., Attia, N. K., Sibak, H. A., El Sheltawy, S. T., \& ElDiwani, G. I. (2008). Production optimization and quality assessment of biodiesel from waste vegetable oil. Int. J. Environ. Sci. Technol. 
Reyes, J. F., Malverde, P. E., Melin, P. S., \& De Bruijn, J. P. (2010). Biodiesel production in a jet flow stirred reactor. Fuel Journal.

Sahoo, P. K., \& Das, L. M. (2009). Process optimization for biodiesel production from Jatropha, Karanja and Polanga oils. Fuel, 88, 1588-1594. http://dx.doi.org/10.1016/j.fuel.2009.02.016

Van Gerpen, J., Shanks, B., \& Pruszko, R. (August 2002-January 2004). Biodiesel Production Technology. Iowa State University.

Vicente, G., Martinez, M., Aracil, J., \& Esteban, A. (2005). Kinetics of sunflower oil methanolysis. Ind. Eng. Chem. Res, 44, 5447-5454. http://dx.doi.org/10.1021/ie040208j

Von Blottnitz, H., Sadat-Rezai, S. A., \& Vardy, J. (2004). Conversion of plant oils to methyl-ester fuels: consideration for reactor design in commercial and small-scale production. In: 16th International Congress of Chemical and Process Engineering, CHISA 2004, 22-26 August, Prague, Czech Republic. 1361.

Table1. Comparison of fuel properties with standards

\begin{tabular}{|c|c|c|c|c|c|c|c|}
\hline Fuel property & Unit & $\begin{array}{c}\text { Measured } \\
\text { amount }\end{array}$ & $\begin{array}{c}\text { ASTM } \\
\text { D6751 } \\
\text { standard } \\
\text { method }\end{array}$ & $\begin{array}{c}\text { ASTM } \\
\text { D6751 } \\
\text { standard } \\
\text { limits }\end{array}$ & $\begin{array}{c}\text { EN14214 } \\
\text { standard } \\
\text { method }\end{array}$ & $\begin{array}{c}\text { EN14214 } \\
\text { standard } \\
\text { limits }\end{array}$ & Report \\
\hline Flash point & ${ }^{\circ} \mathrm{C}$ & 175 & D93 & $>130$ & ISO CD $3679 \mathrm{e}$ & $>101$ & normal \\
\hline $\begin{array}{l}\text { Dynamic } \\
\text { viscosity }\end{array}$ & $\begin{array}{c}\mathrm{mPa} \cdot \mathrm{s} \text { in } \\
40^{\circ} \mathrm{C}\end{array}$ & 4.0955 & D445 & $\begin{array}{c}1.6438- \\
5.1912\end{array}$ & EN ISO 3104 & $\begin{array}{c}3.0282- \\
4.3260\end{array}$ & normal \\
\hline density & $\begin{array}{c}\mathrm{g} / \mathrm{cm}^{3} \text { in } \\
40^{\circ} \mathrm{C}\end{array}$ & 0.8652 & - & - & $\begin{array}{c}\text { EN ISO } 3675 / \mathrm{EN} \\
\text { ISO } 12185\end{array}$ & $\begin{array}{c}0.860-0.900 \\
\left(\text { at } 15^{\circ} \mathrm{C}\right)\end{array}$ & normal \\
\hline $\begin{array}{l}\text { Water content } \\
\text { and sediment }\end{array}$ & $\begin{array}{c}\% \\
\text { volume }\end{array}$ & 0.0195 & D2709 & $<0.050$ & $\begin{array}{l}\text { EN ISO } 12937 \\
\text { (only for water } \\
\text { content) }\end{array}$ & $<0.050$ & normal \\
\hline Acid value & $\begin{array}{c}\mathrm{mg} \\
\mathrm{KOH} / \mathrm{g}\end{array}$ & 0.412 & D664 & $<0.8$ & EN14104 & $<0.5$ & normal \\
\hline $\begin{array}{l}\text { Carbon } \\
\text { residue }\end{array}$ & $\% w t$ & 0.0 & D4530 & $<0.05$ & EN590 & $<0.3$ & normal \\
\hline Free glycerine & $\% \mathrm{wt}$ & 0.007 & D6584 & $<0.02$ & $\begin{array}{c}\text { EN14105m/EN1 } \\
4109\end{array}$ & $<0.02$ & normal \\
\hline
\end{tabular}




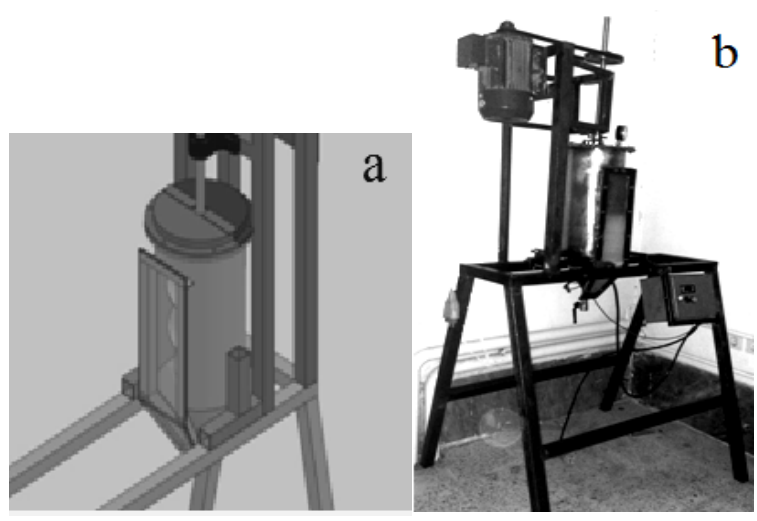

Figure 1. (a) computer aided design; (b) manufactured BSTR in Urmia University

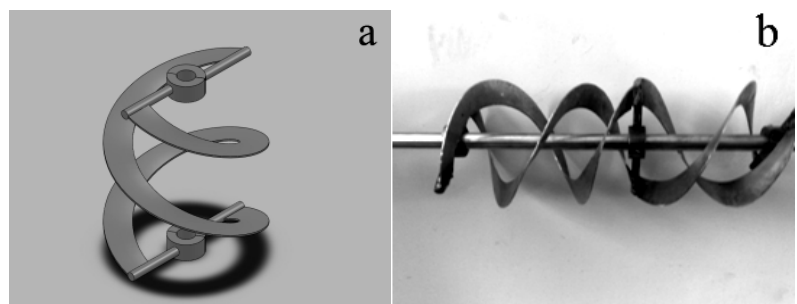

Figure 2. A helical ribbon-like stirrer: (a) designed in SolidWorks software; (b) manufactured

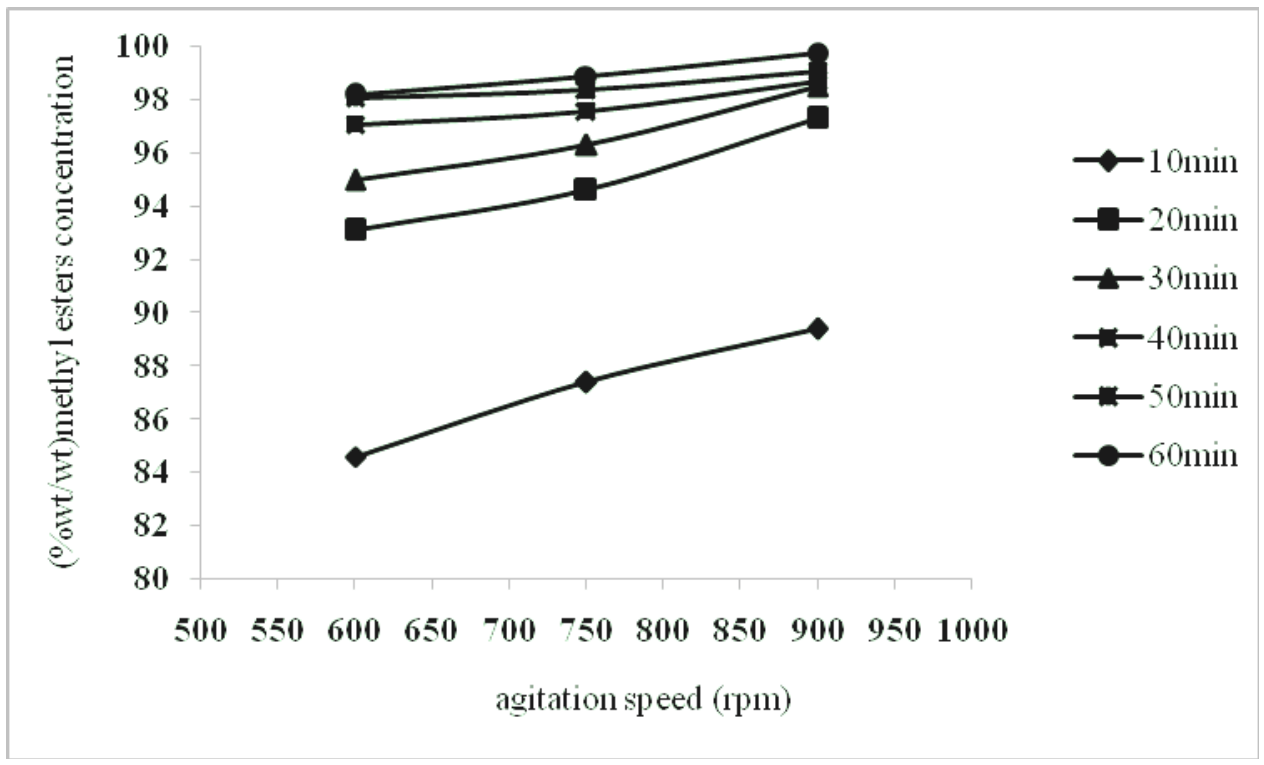

Figure 3. The effect of agitation speed on transesterification reaction in $64{ }^{\circ} \mathrm{C}, 6: 1$ molar ratio, and $\mathrm{KOH}$ in $1 \% \mathrm{wt}$ oil 